\title{
Increasing iridium oxide activity for the oxygen evolution reaction with hafnium modification
}

Fang Zhao, ${ }^{\text {all }}$ Bo Wen, ${ }^{\text {b\&dl }}$ Wenhan Niu, ${ }^{\mathrm{c}}$ Zhu Chen, ${ }^{\text {e\# }}$ Chao Yan, ${ }^{\mathrm{d}}$ Annabella Selloni, ${ }^{\mathrm{b}}$ Christopher G. Tully, ${ }^{a}$ Xiaofang Yang, ${ }^{\text {c\$* }}$ and Bruce E. Koel ${ }^{* *}$

\footnotetext{
${ }^{a}$ Department of Physics, Princeton University, New Jersey, 08544, United States

${ }^{\mathrm{b}}$ Department of Chemistry, Princeton University, New Jersey, 08544, United States

${ }^{c}$ Department of Chemical and Biological Engineering, Princeton University, New Jersey, 08540, United States

${ }^{\mathrm{d}}$ Department of Mechanical and Aerospace Engineering, Princeton University, New Jersey, 08540, United States
} 


\section{Table of Contents}

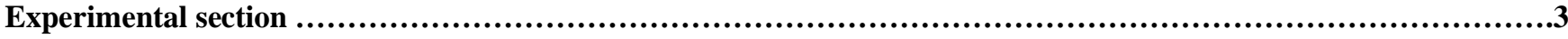

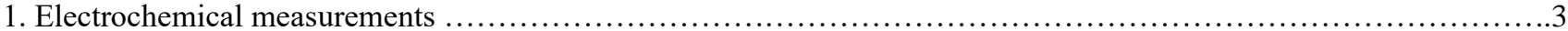

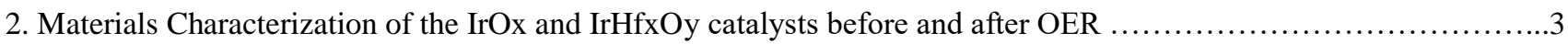

3. Operando Surface Enhanced Raman scattering (SERS) of the IrOx and IrHfxOy catalysts during OER ................

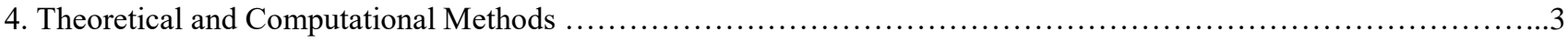

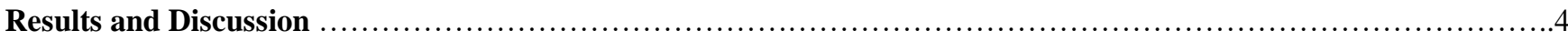

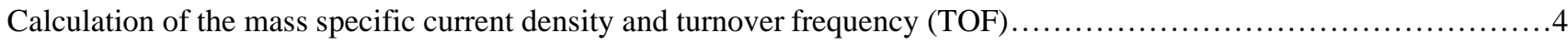

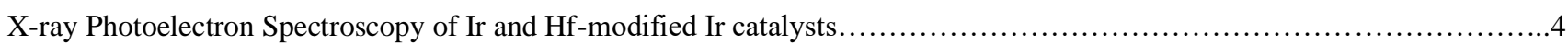

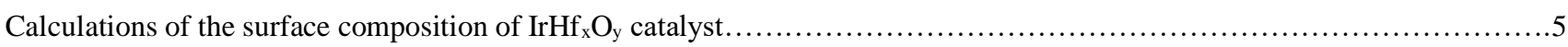

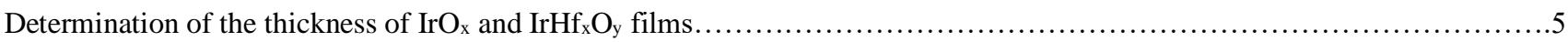

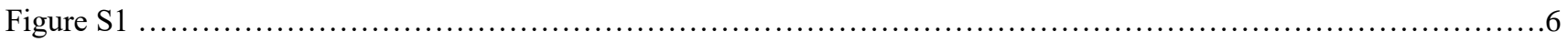

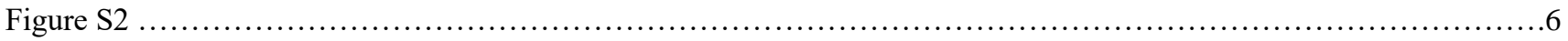

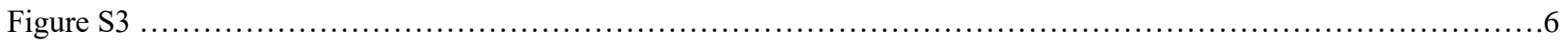

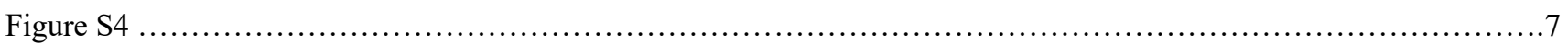

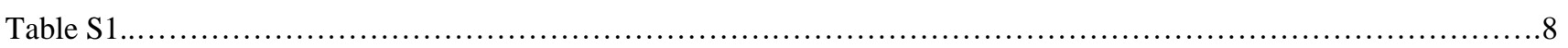

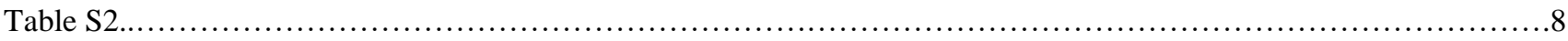

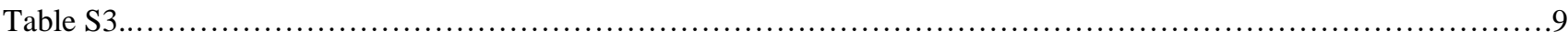

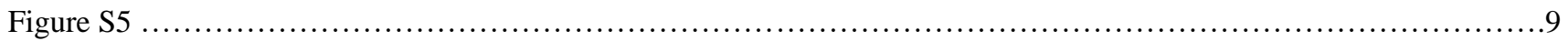

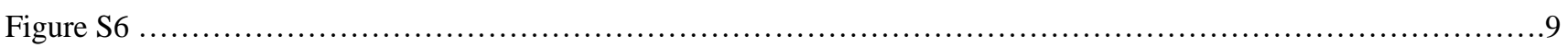

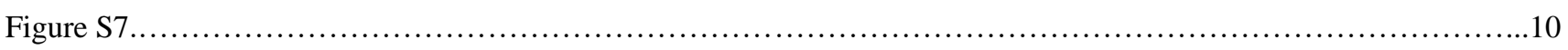

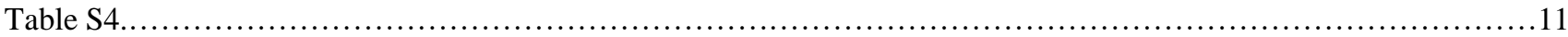

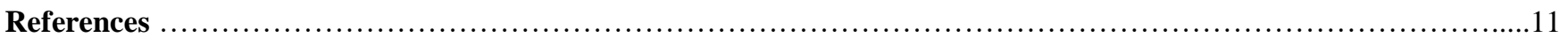




\section{Experimental Section}

\section{Electrochemical measurements}

Metallic polycrystalline Ir and $\mathrm{HfIr}_{3}$ round discs ( $5 \mathrm{~mm}$ diameter, $1.5 \mathrm{~mm}$ thick) were polished using 1- $\mu \mathrm{m} \mathrm{Al}_{2} \mathrm{O}_{3}$ powder until flat surfaces with a mirror finish were obtained. The $\mathrm{HfIr}_{3}$ sample had a bulk concentration of $25 \% \mathrm{Hf}$ and $75 \% \mathrm{Ir}$. After polishing, the surfaces were ultrasonically cleaned in deionized water. A polished sample was then loaded on a Rotating Disc Electrode (RDE) (Pine E4TQ Series) apparatus for electrochemical measurements. The sample was immersed in $\mathrm{O}_{2}$-purged solutions of either $0.1 \mathrm{M}$ $\mathrm{KOH}$ or $0.1 \mathrm{M} \mathrm{HClO}_{4}$ for RDE electrochemical measurements. A standard three-electrode electrochemical cell was used with a Ptwire counter electrode and an $\mathrm{Ag} / \mathrm{AgCl}$ reference electrode. During OER polarization testing, the sample was scanned from 1.3 to $1.7 \mathrm{~V}$ on the RHE scale. This lower limit of $1 \mathrm{~V}$ for the potential was chosen to avoid reduction reactions of the surface oxide during OER scans. After electrochemical measurements by cyclic voltammetry (CV) scanning at $4500 \mathrm{rpm}$ between 1.3 to $1.7 \mathrm{~V}$ for $30 \mathrm{~min}$, the sample was removed from the RDE apparatus. It was then quickly rinsed by pure deionized water using a pipette and dried by blowing off the water droplet on the sample surface just prior to materials analysis as described below. The OER polarization curves are plotted with the $\mathrm{x}$-axis on the RHE scale. The zero-potential was determined by the onset of the HER and HOR in CV scans using a polycrystalline Pt electrode immersed in a $\mathrm{H}_{2}$-purged solution of $0.1 \mathrm{M} \mathrm{KOH}$ or $0.1 \mathrm{M} \mathrm{HClO}_{4}$, as shown in Figure S1. This allowed comparison of the OER activity at two widely different $\mathrm{pH}$ values. In all such plots shown, the OER activity was normalized to the geometrical surface area of the electrode surface and the weight of Ir oxide. The reported turnover frequency was also obtained as normalized in this same manner.

\section{Materials Characterization of the $\operatorname{IrO}_{\mathrm{x}}$ and $\operatorname{IrHf}_{\mathrm{x}} \mathrm{O}_{\mathrm{y}}$ catalysts before and after OER}

The morphology and composition of these polished samples were analyzed by atomic force microscopy (AFM), scanning electron microscopy (SEM), energy-dispersive X-ray spectroscopy (EDX), and X-ray photoelectron spectroscopy (XPS). AFM topographic imaging of the Ir oxide and Hf-modified Ir oxide catalysts after polishing and after OER measurements was done using a Bruker NanoMan AFM instrument. SEM imaging was done with a Verios 460 High Resolution SEM, which has an Oxford EDX spectrometer installed inside the chamber for elemental mapping and analysis. The SEM images were obtained using a beam at 5 $\mathrm{kV}$ and $50 \mathrm{pA}$. XPS spectra from the samples were obtained using a Thermo K-Alpha Plus Photoelectron Spectrometer operating with a monochromatic $\mathrm{Al} \mathrm{K} \alpha \mathrm{X}$-ray source, $400 \mu \mathrm{m}$ analysis spot size, and $20 \mathrm{eV}$ pass energy. To obtain the bulk $\mathrm{Hf} / \mathrm{Ir}$ atomic ratio, the sample was sputtered by $1 \mathrm{keV} \mathrm{Ar}{ }^{+}$ions at $30 \mathrm{nA}$ beam current for $5 \mathrm{~min}$. XPS binding energies (BE) are reported referenced to the $\mathrm{Au} 4 \mathrm{f}_{7 / 2}$ peak at $84.0 \mathrm{eV}$ from clean $\mathrm{Au}$. Reported binding energies herein for the Ir and Hf-modified Ir catalysts are those values obtained while using the custom charge neutralization system on the Thermo K-Alpha system.

\section{Operando Surface Enhanced Raman scattering (SERS) of the $\operatorname{IrO}_{\mathrm{x}}$ and $\operatorname{IrHf}_{\mathrm{x}} \mathrm{O}_{\mathrm{y}}$ catalysts during $\mathrm{OER}$}

A custom-made electrochemical cell was used for operando Raman spectroscopy experiments, as detailed in a previous study. ${ }^{1}$ In one experiment, a roughened Au substrate coated with $10 \mathrm{~nm}$ of Ir and Hf-modified Ir (with the same composition as the HfIr disc $^{2}$ defined by XPS) prepared using $\mathrm{Ar}^{+}$sputter deposition, was used as the working electrode. The roughened $\mathrm{Au}$ substrate was first prepared electrochemically by five times cyclically scanning, with 20 cycles for each time, at $0.5 \mathrm{~V} \mathrm{~s}^{-1}$ in a $0.1 \mathrm{M} \mathrm{KCl}$ solution between -0.25 to $1.28 \mathrm{~V}$ vs. $\mathrm{Ag} / \mathrm{AgCl}$, followed by reduction at $-0.25 \mathrm{~V}$ for $5 \mathrm{~min}$. A platinum wire (Pine Research Instrument, AFCTR5) and an $\mathrm{Ag} / \mathrm{AgCl}$ electrode (Bioanalytical Systems Incorporation, MF-2021) served as the counter and reference electrodes, respectively. A potentiostat (Pine Research Instrument, WaveNow) was used to apply potentials to the working electrode while Raman spectra were being acquired. A confocal Raman microscope (Horiba, LabRAM Aramis) was used to acquire operando Raman spectra using a $533 \mathrm{~nm}$ laser with an acquisition time of $20 \mathrm{~s}$ for each spectrum.

\section{Theoretical and Computational Methods}

Spin-polarized density functional theory (DFT) calculations were performed using the $\mathrm{PBE}^{2}$ functional as implemented in the CP2K package. ${ }^{3,4}$ Electron-ion interactions were described by norm-conserved Goedecker-Teter-Hutter (GTH) pseudopotentials ${ }^{5}$ and a hybrid Gaussian planewave basis set with a cutoff energy of $320 \mathrm{Ry}$ was used to represent the valence electron wavefunctions. All the atoms were relaxed until residual forces were smaller than $0.02 \mathrm{eV} / \AA ̊$.

The OER activity was investigated using periodic slab models of the (110) surface of pristine rutile $\mathrm{IrO}_{2}$ and $\mathrm{Hf}$-doped $\mathrm{Hf}_{0.25} \mathrm{Ir}_{0.75} \mathrm{O}_{2}$ crystals. We note that a similar model was used to describe the reactivity of $\mathrm{IrO}_{\mathrm{x}}$ in a recent study. ${ }^{6}$ Each slab included four oxide layers and a $(4 \times 2)$ surface supercell (Figure 4$)$ and repeated slabs were separated by $12 \AA$ of vacuum along the $z$ direction. Given the large size of these models, only the $\Gamma$ point was used to sample the reciprocal lattice. As shown in Figure 4, rutile (110) surfaces expose alternate rows of 5-coordinated $\mathrm{Ir} / \mathrm{Hf}$ and 2-coordinated $\mathrm{O}$ sites along the [001] direction. $\mathrm{The} \mathrm{Hf}_{0.25} \mathrm{Ir}_{0.75} \mathrm{O}_{2}$ slab was generated by regularly distributing the $\mathrm{Hf}$ dopants into each layer, whereas on the surface the $\mathrm{Hf}$ positions were adjusted to realize different 
types of water adsorption (i.e., under-coordinated metal) sites. The OER activities of three inequivalent sites were compared: I near Hf; II between Ir; and III between Hf. For simplicity, free energies were approximated by total energies for this comparison.

\section{Results and Discussion}

\section{Calculation of the mass specific current density and turnover frequency (TOF)}

The measured current density $(I)$ can be normalized to the weight of the catalyst, which in our case is the weight of the Ir oxide in the oxide layer, to obtain the mass specific current density $\left(I_{m}\right)$ per gram Ir oxide, as given below

$$
I_{m}=\frac{\mathbf{I}_{\mathbf{A}}}{\mathbf{d} \times \boldsymbol{\rho} \times \boldsymbol{p}_{\mathbf{I r}}}
$$

where $I_{\mathrm{A}}$ is the current density normalized to the geometrical surface area $\left(\mathrm{A} \mathrm{cm}^{-2}\right), d$ is the oxide thickness $(\mathrm{cm}), \rho$ is the density of Ir oxide $\left(11.66 \mathrm{~g} \mathrm{~cm}^{-3}\right)$ assuming the density of the surface oxide is same as the that of pure $\mathrm{IrO}_{2}$, and $p_{\text {Ir }}$ is the percentage of $\mathrm{Ir}$ oxide in the surface oxide layer. Table S1 compares the mass activity calculated in our work to that of some other hybrid Ir catalysts.

Example of calculating $I_{\mathrm{m}}$ on an $\mathrm{IrHf}_{\mathrm{x}} \mathrm{O}_{\mathrm{y}}$ catalyst under acidic conditions:

Current density $\left(\mathrm{A} \mathrm{cm}^{-2}\right)$ :

$$
4.4 \times 10^{-6} \mathrm{~A} \mathrm{~cm}^{-2} \text { at } 0.3 \mathrm{~V} \text { overpotential }
$$

Mass of $\mathrm{IrO}_{2}$ on $1 \mathrm{~cm}^{2}$ electrode:

$$
0.8 \mathrm{~nm} \times 10^{-7} \mathrm{~cm} \mathrm{~nm}^{-1} \times 11.66 \mathrm{~g} \mathrm{~cm}^{-3} \times 68 \%=6.34 \times 10^{-7} \mathrm{~g} \mathrm{~cm}^{-2}
$$

Mass specific current density:

$$
\left(4.4 \times 10^{-6} \mathrm{~A} \mathrm{~cm}^{-2}\right) /\left(6.34 \times 10^{-7} \mathrm{~g} \mathrm{~cm}^{-2}\right)=6950 \mathrm{~A} \mathrm{~g}^{-1}
$$

The turnover frequency (TOF) is defined as the number of molecules converted per second per Ir site on the surface oxide layer. So

$$
\mathrm{TOF}=\frac{I_{m} \times C \times \frac{1}{n_{e}}}{\frac{1 g}{m} \times N A}
$$

where $\mathrm{I}_{\mathrm{m}}$ is the mass specific current density, $\left(\mathrm{A}_{\mathrm{IrOx}}{ }^{-1}\right)$, and one amp $(\mathrm{A})$ is one coulomb $(\mathrm{C})$ per second, $\mathrm{C}$ is the charge per coulomb, $6.242 \times 1018 \mathrm{e} \mathrm{C}^{-1}, n_{\mathrm{e}}$ is the number of charges transferred associated with the conversion of one water molecule, $m$ is the molar mass of $\mathrm{IrO}_{2}\left(224.22 \mathrm{~g} \mathrm{~mole}^{-1}\right)$, and $N_{\mathrm{A}}$ is Avogadro's constant $\left(6.022 \times 10^{23} \mathrm{~mol}^{-1}\right)$.

Example of calculating TOF for a $\operatorname{IrHf}_{\mathrm{x}} \mathrm{O}_{\mathrm{y}}$ catalyst under acidic conditions:

Mass current density:

$$
I_{\mathrm{m}}=6950 \mathrm{~A} \mathrm{~g}^{-1} \text { or } 6950 \mathrm{C} \mathrm{s}^{-1} \mathrm{~g}^{-1}
$$

Number of charges transferred per second per gram:

$$
6950 \mathrm{C} \mathrm{s}^{-1} \mathrm{~g}^{-1} \times 6.242 \times 1018 \mathrm{e} \mathrm{C}^{-1}=4.338 \times 1022 \mathrm{e} \mathrm{s}^{-1} \mathrm{~g}^{-1}
$$

Number of water molecules (4 electrons per $\mathrm{H}_{2} \mathrm{O}$ ) converted per second per gram $\mathrm{IrO}_{2}$ :

$$
4.338 \times 10^{22} \mathrm{e} \mathrm{cm}^{-2} / 4=1.0845 \times 1022 \mathrm{~s}^{-1} \mathrm{~g}^{-1}
$$

Moles of $\mathrm{Ir}$ atoms or $\mathrm{IrO}_{2}$ per gram $\mathrm{IrO}_{2}$ :

$$
1 \mathrm{~g} /\left(224.22 \mathrm{~g} \mathrm{~mole}^{-1}\right)=4.46 \times 10^{-3} \text { mole g }^{-1}
$$

Number of $\mathrm{Ir}$ atoms or $\mathrm{IrO}_{2}$ per gram $\mathrm{IrO}_{2}$ :

$$
\begin{gathered}
4.46 \times 10^{-3} \mathrm{~mole} \mathrm{~g}^{-1} \times 6.022 \times 10^{23} \mathrm{~mol}^{-1}=2.6857 \times 10^{21} \text { mole g}^{-1} \\
\text { TOF }=\left(1.0845 \times 10^{22} \mathrm{~s}^{-1} \mathrm{~g}^{-1}\right) /\left(2.6857 \times 10^{21} \mathrm{~mole} \mathrm{~g}^{-1}\right)=4.04 \mathrm{~s}^{-1}
\end{gathered}
$$

\section{X-ray Photoelectron Spectroscopy of Ir and Hf-modified Ir catalysts}

Figure S4 and Table S2 summarize all the XPS analysis results for the different samples. Reported peak positions were referenced to the $\mathrm{Au} 4 \mathrm{f}_{7 / 2}$ XPS peak at $84.0 \mathrm{eV} \mathrm{BE}$. The sensitivity factor ratio of $\mathrm{Hf} 4 \mathrm{f}$ : Ir $4 \mathrm{f}$ was found to be to 1:2.5 based on the XPS peak intensities from the bulk atomic ratio of the HfIr 3 alloy sample. The binding energies of the Hf $4 \mathrm{f}_{7 / 2}$ and Ir $4 \mathrm{f}_{7 / 2} \mathrm{XPS}_{\mathrm{Peaks}}$ of

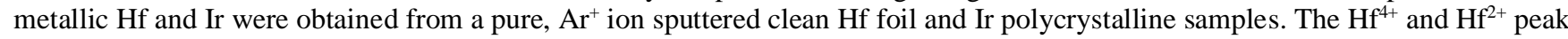
assignments were based on our previous paper. ${ }^{7}$ 


\section{Calculations of the surface composition of the $\operatorname{IrHf}_{x} \mathrm{O}_{\mathrm{y}}$ catalyst}

Determination of the atomic concentrations in the near-surface oxide layers was based on XPS measurements. The oxide components (Hf4f,ox and Ir4f,ox) of the Hf $4 \mathrm{f}$ and Ir $4 \mathrm{f}$ XPS peaks were used to determine the atomic concentration of Hf. Assuming uniform mixing of $\mathrm{Hf}$ and $\mathrm{Ir}$ in the surface oxide layers, the Hf oxide at.\% is calculated as:

$$
\text { Hf oxide } \%=\frac{H f 4 f, o x / S_{H f 4 f}}{H f 4 f, o x / S_{H f 4 f}+\operatorname{Ir} 4 f \text { ox } / S_{I r 4 f}} \times 100
$$

where $S_{H f 4 f}$ and $S_{I r 4 f}$ are the XPS sensitivity factors for Hf and Ir, respectively. The Hf oxide concentration after OER in $0.1 \mathrm{M}$ $\mathrm{HClO}_{4}$ was $32 \%$, whereas after the OER in $0.1 \mathrm{M} \mathrm{KOH}$, the surface contained only $18 \%$ Hf oxide.

\section{Determination of the thickness of $\operatorname{IrO}_{x}$ and $\operatorname{IrHf}_{x} O_{y}$ films}

Quantification of the $\mathrm{IrO}_{\mathrm{x}}$ and $\operatorname{IrHf}_{\mathrm{x}} \mathrm{O}_{\mathrm{y}}$ oxide thickness was based on the attenuation of the substrate $\mathrm{Ir}$ 4f peak intensity by the surface oxide layer. Assuming a layer-by-layer growth mode of the surface oxide film (the oxide layer thickness and density are uniform), the photoelectron intensity of the metallic $\mathrm{Ir} 4 \mathrm{f}_{7 / 2}$ peak from the Ir or Hf-modified Ir substrate $I_{I r}$, decreases with oxide film thickness $d$ as: $^{8}$

$$
I_{I r}=I_{I r}^{\infty} \exp \left(-\frac{d}{\lambda_{i m f p}^{I r}\left(E_{I r}\right) \cos \theta}\right)
$$

where $I_{I r}$ is the peak intensity of the metallic component of the $\operatorname{Ir} 4 \mathrm{f}_{7 / 2}$ peak after OER in $0.1 \mathrm{M} \mathrm{HClO}_{4}$ or $\mathrm{KOH}_{\mathrm{Ir}}^{\infty}$ is the $\mathrm{Ir} 4 \mathrm{f}_{7 / 2}$ peak intensity after sputter-cleaning, $\lambda_{i m f p}^{I r}$ is the inelastic mean free path of $\mathrm{Ir}_{4} \mathrm{f}_{7 / 2}$ electrons (1425 eV kinetic energy) in Ir oxide or Hf-modified Ir oxide. Since we estimate that the oxide film on Hf-modified Ir electrode consists of 68-82\% Ir oxide (Table S2), the mean free path of $\mathrm{Ir}_{4 \mathrm{f}_{7 / 2}}$ electrons at $1425 \mathrm{eV}$ in $\mathrm{IrO}_{2}$ was used for all calculations. The value of $\lambda_{\text {imfp }}^{I r}$ of $\mathrm{IrO}_{2}$ is given as $1.9 \mathrm{~nm}$ in ref. [9]. The thickness of the Ir oxide or Hf-modified Ir oxide is calculated to be $0.8-1.5 \mathrm{~nm}$. The calculation details are shown in Table S3. 

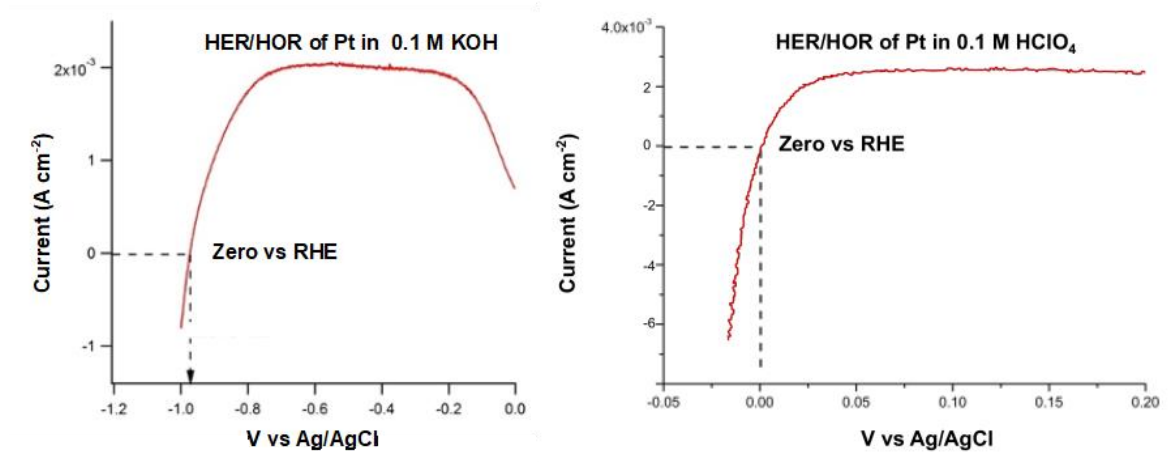

Figure S1. Determination of the zero-potential vs. RHE using linear sweep voltammetry (LSV) by measuring the HER/HOR activity of a polycrystalline Pt electrode in $0.1 \mathrm{M} \mathrm{KOH} \mathrm{(left} \mathrm{panel)} \mathrm{and} 0.1 \mathrm{M} \mathrm{HClO}_{4}$ (right panel). The zero potential is that potential where no current is observed. As shown in this figure, $-0.973 \mathrm{~V} \mathrm{vs}$. $\mathrm{Ag} / \mathrm{AgCl}$ is the zero-potential vs RHE and this value was used to adjust the $\mathrm{x}$-axis in the OER plots shown.
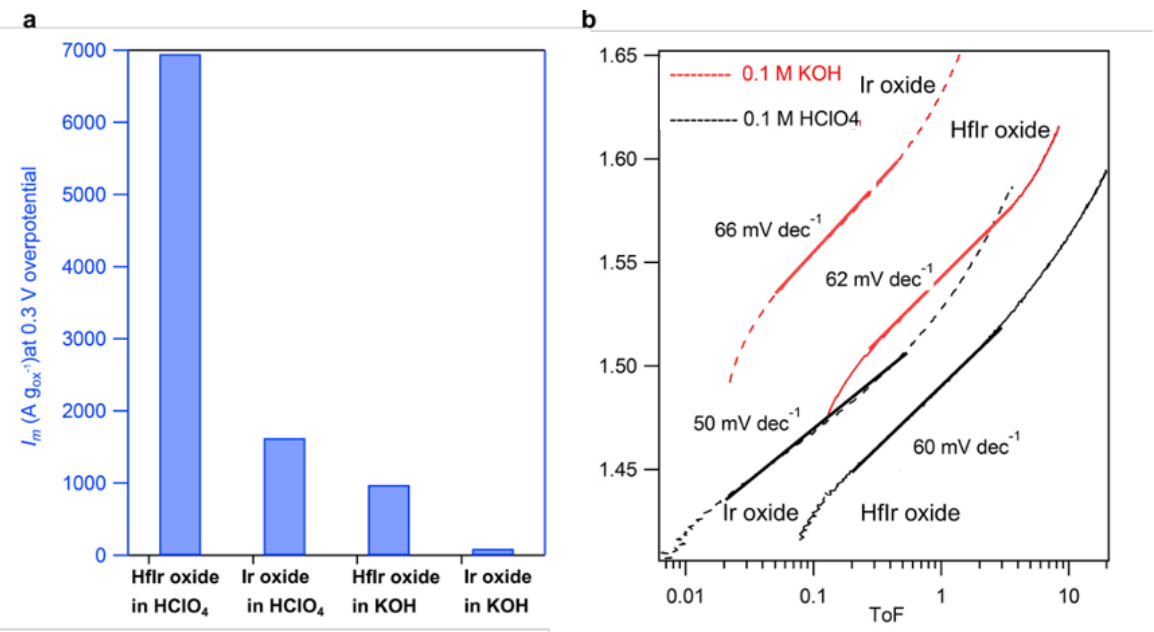

Figure S2. (a) Mass specific activities normalized for the mass of $\mathrm{IrO}_{2}$ in the surface oxide film. (b) Tafel plots comparing the performance of $\mathrm{IrO}_{\mathrm{x}}$ and $\mathrm{IrHf}_{\mathrm{x}} \mathrm{O}_{\mathrm{y}}$ surface oxide layers at $\eta=0.3 \mathrm{~V}$ in acidic and alkaline conditions.

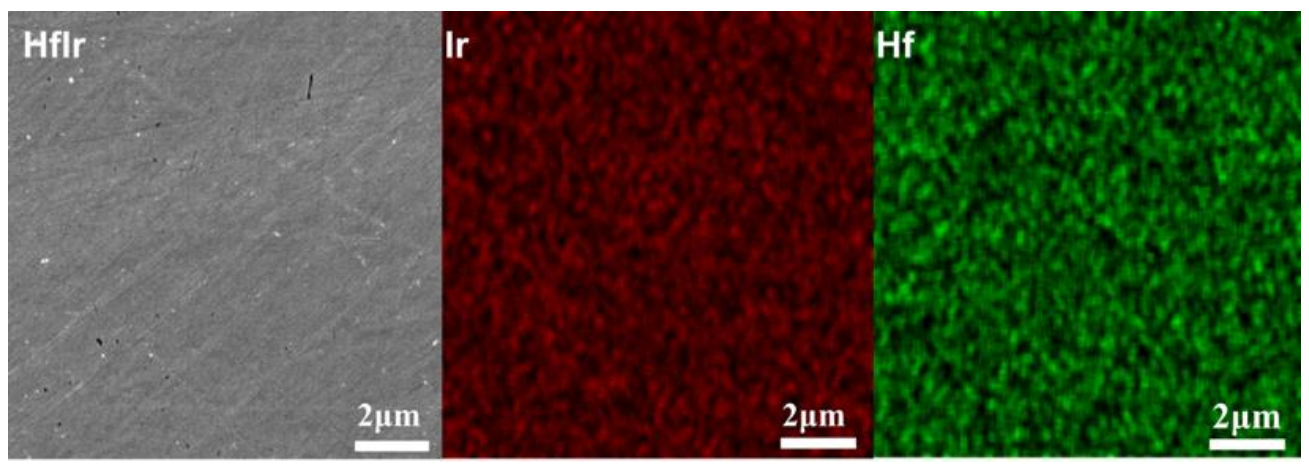

Figure S3. SEM image (left panel) and EDX elemental maps for the "as polished" Hf-modified Ir catalyst obtained before OER reactions. 

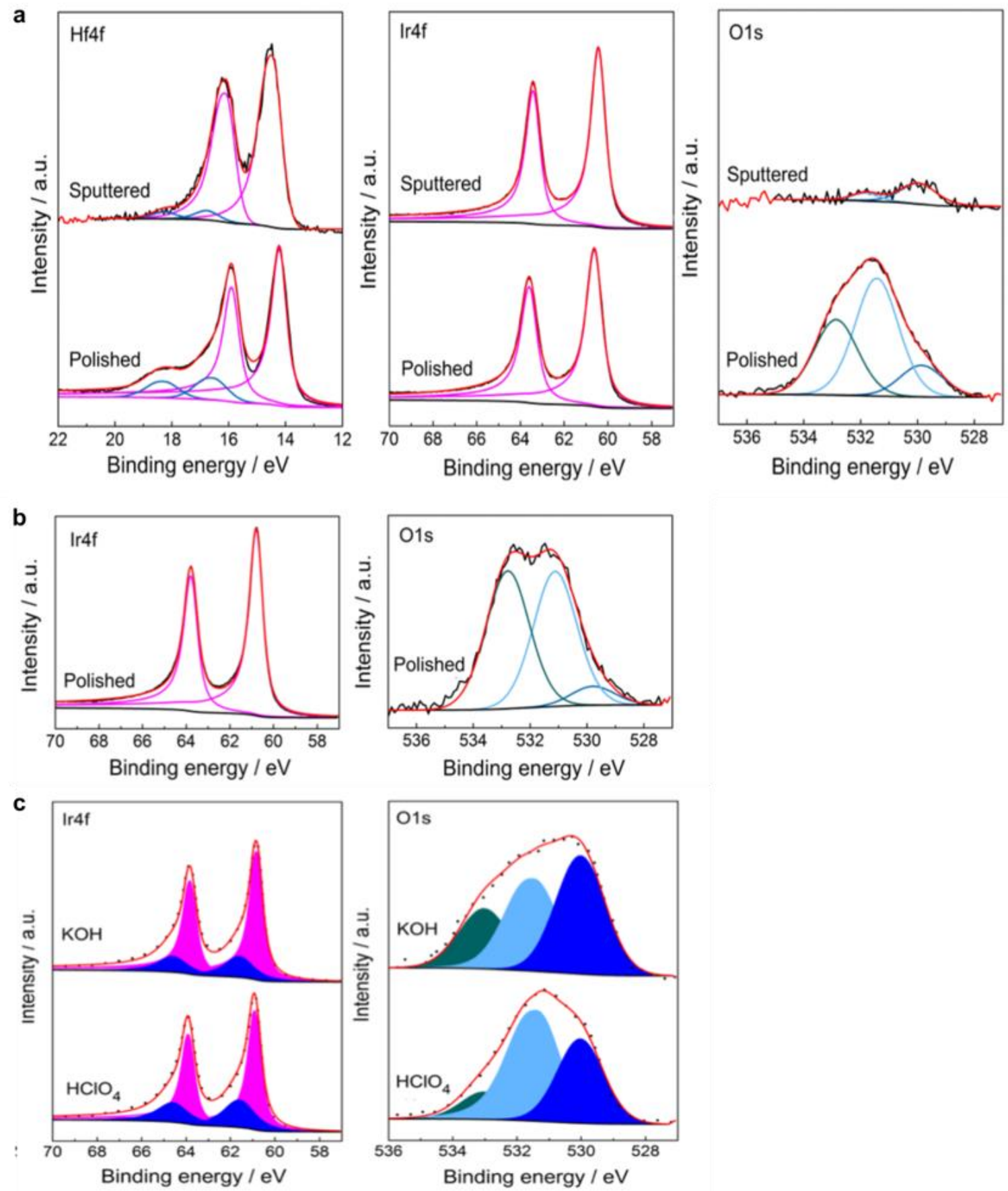

Figure S4. XPS spectra from (a) polished and sputtered Hf-modified Ir electrodes before OER, (b) polished Ir electrodes before OER, and (c) polished Ir electrodes after OER in $0.1 \mathrm{M} \mathrm{KOH}$ and $0.1 \mathrm{M} \mathrm{HClO}_{4}$. 
Table S1. Comparison of Ir-based catalyst mass activity in acidic conditions

\begin{tabular}{|c|c|c|c|c|}
\hline Sample & Ref. & Mass activity (A mgIr-1) & V vs RHE (V) & Electrolyte \\
\hline $\operatorname{IrHf}_{x} O_{y}$ & This work & 6.95 & 0.3 (overpotential) & $0.1 \mathrm{M} \mathrm{HClO}_{4}$ \\
\hline Ir-Ni nanowires & 10 & 3 & 1.6 & $0.1 \mathrm{M} \mathrm{HClO}_{4}$ \\
\hline Ir-Co nanowires & 10 & 2.1 & 1.6 & $0.1 \mathrm{M} \mathrm{HClO}_{4}$ \\
\hline Ir-Ni nanoframes & 11 & 0.22 & 1.51 & $0.1 \mathrm{M} \mathrm{HClO}_{4}$ \\
\hline Rh-Ir nanoparticles & 12 & 1.17 & 0.3 (overpotential) & $0.5 \mathrm{M} \mathrm{H}_{2} \mathrm{SO}_{4}$ \\
\hline Nanoporous $\operatorname{Ir}_{70} \mathrm{Ni}_{15} \mathrm{Co}_{15}$ & 13 & 0.045 & 1.5 & $0.1 \mathrm{M} \mathrm{HClO}_{4}$ \\
\hline Ir nanodendrites /ATO & 14 & 0.07 & 1.51 & $0.05 \mathrm{M} \mathrm{H}_{2} \mathrm{SO}_{4}$ \\
\hline $\mathrm{IrO}_{\mathrm{x}} / \mathrm{Nb}-\mathrm{SnO}_{2}$ & 15 & 10 & 1.5 & $0.1 \mathrm{M} \mathrm{HClO}_{4}$ \\
\hline $\mathrm{IrO}_{\mathbf{x}} / \mathrm{Ta}-\mathrm{SnO}_{2}$ & 15 & 15 & 1.5 & $0.1 \mathrm{M} \mathrm{HClO}_{4}$ \\
\hline
\end{tabular}

Table S2. Summary of XPS results including peak binding energies and peak areas for catalysts before and after OER in 0.1 $\mathrm{M} \mathrm{KOH}$ and $0.1 \mathrm{M} \mathrm{HClO}_{4}$.

\begin{tabular}{|c|c|c|c|c|c|c|c|c|c|}
\hline \multirow[t]{2}{*}{ Sample } & & \multicolumn{2}{|c|}{ Hf $\mathbf{4} \mathbf{f}_{7 / 2}$} & \multicolumn{2}{|c|}{$\operatorname{Ir} \mathbf{4} \mathbf{f}_{7 / 2}$} & \multicolumn{4}{|c|}{ O 1s } \\
\hline & & $\mathbf{H f}^{\mathbf{0}}$ & $\mathbf{H} \mathbf{f}^{2+}$ & $\mathbf{H f}^{4+}$ & $\mathbf{I r}^{0}$ & $\mathrm{Ir}^{4+}$ & $\mathrm{O}^{2-}$ & $\mathbf{O H}^{-}$ & $\mathrm{H}_{2} \mathrm{O}$ \\
\hline \multirow{3}{*}{$\begin{array}{l}\text { Hf-modified } \\
\text { Ir sputtered }\end{array}$} & Binding energy (eV) & 14.4 & & & 60.4 & & & & \\
\hline & Peak area (a.u.) & 44.4 & & & 332 & & & & \\
\hline & Atomic \% & \multicolumn{2}{|c|}{25} & \multicolumn{2}{|c|}{75} & & & & \\
\hline \multirow{2}{*}{$\begin{array}{l}\text { Hf foil } \\
\text { sputtered }\end{array}$} & Binding energy (eV) & 14.4 & & & & & & & \\
\hline & Peak area (a.u.) & 161 & & & & & & & \\
\hline \multirow[t]{2}{*}{ Ir sputtered } & Binding energy (eV) & & & & 60.9 & & & & \\
\hline & Peak area (a.u.) & & & & 480 & & & & \\
\hline \multirow{2}{*}{$\begin{array}{l}\text { Hf-modified } \\
\text { Ir polished }\end{array}$} & Binding energy (eV) & 14.3 & 16.5 & & 60.6 & & 530 & 531.5 & 533 \\
\hline & Peak area (a.u.) & 18.7 & 2.27 & & 240.8 & & 5.5 & 21 & 13.5 \\
\hline \multirow[t]{2}{*}{ Ir polished } & Binding energy (eV) & & & & 60.8 & & 530 & 531.5 & 533 \\
\hline & Peak area (a.u.) & & & & 369 & & 1.9 & 14.3 & 14.4 \\
\hline \multirow{3}{*}{$\begin{array}{l}\text { Hf-modified } \\
\text { Ir after } \\
\text { OER in } 0.1 \\
M \text { HClO4 }\end{array}$} & Binding energy (eV) & 14.3 & 16.4 & 17.4 & 60.8 & 61.5 & 530 & 531.5 & 533 \\
\hline & Peak area (a.u.) & 4.1 & 3 & 4.2 & 220 & 38.5 & 18.1 & 41.88 & 9.9 \\
\hline & Atomic \%, ox & \multicolumn{2}{|c|}{32} & \multicolumn{2}{|c|}{68} & & & & \\
\hline \multirow{3}{*}{$\begin{array}{l}\text { Hf-modified } \\
\text { Ir after } \\
\text { OER in } 0.1 \\
\text { M KOH }\end{array}$} & Binding energy (eV) & 14.3 & 16.4 & 17.4 & 60.7 & 61.5 & 530 & 531.5 & 533 \\
\hline & Peak area (a.u.) & 12.9 & 3.7 & 0 & 190 & 43.2 & 25.4 & 17.7 & 6.5 \\
\hline & Atomic \%, ox & \multicolumn{2}{|c|}{18} & \multicolumn{2}{|c|}{82} & & & & \\
\hline \multirow{2}{*}{$\begin{array}{lr}\text { Ir } & \text { after } \\
\text { OER } & \text { in } \\
\text { 0.1M } & \\
\text { HClO4 } & \end{array}$} & Binding energy (eV) & & & & 60.9 & 61.6 & 530 & 531.4 & 533 \\
\hline & Peak area (a.u.) & & & & 210 & 57.6 & 22.2 & 34.2 & 7.2 \\
\hline \multirow{2}{*}{$\begin{array}{lr}\text { Ir } & \text { after } \\
\text { OER } & \text { in } \\
0.1 M & \text { КОН }\end{array}$} & Binding energy (eV) & & & & 60.8 & 61.6 & 530 & 531.4 & 533 \\
\hline & Peak area (a.u.) & & & & 226.7 & 39.7 & 23.3 & 19.6 & 12 \\
\hline
\end{tabular}


Table S3. Calculation of the thickness (d) of the oxide film layer

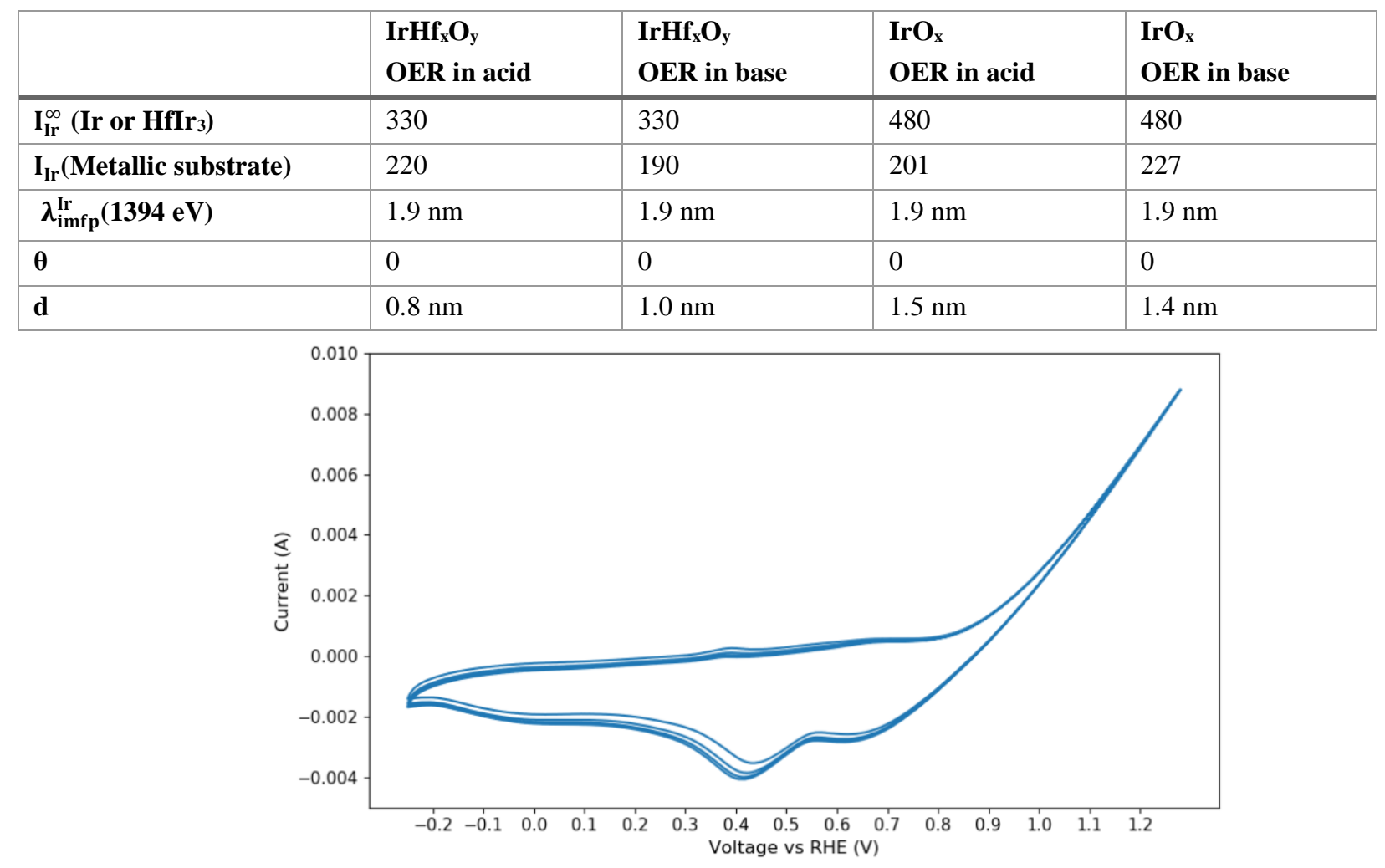

Figure S5. Cyclic voltammetry (CV) scans of the Au foil roughening process in a $0.1 \mathrm{M} \mathrm{KCl}$ solution.

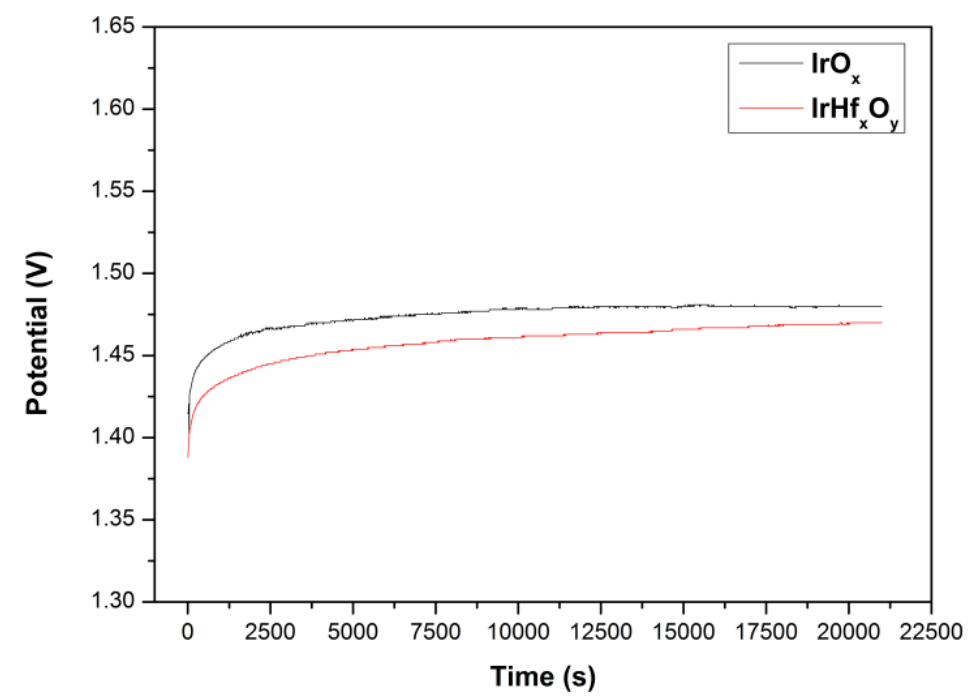

Figure S6. Catalyst stability measurement of $\mathrm{IrO}_{\mathrm{x}}$ and $\mathrm{IrHf}_{\mathrm{x}} \mathrm{O}_{\mathrm{y}}$ films on roughened $\mathrm{Au}$ foil for $6 \mathrm{~h}$. The catalysts were prepared by sputtering $10 \mathrm{~nm}$ films of Ir and Ir-Hf on roughened Au foil, followed by activation using 50 cycles of CV scans (0.2-1.5 V, scan rate $0.01 \mathrm{~V} / \mathrm{s}$ ) in $0.1 \mathrm{M} \mathrm{HClO}_{4}$ prior to the stability measurement. The $\mathrm{IrO}_{\mathrm{x}}$ and $\mathrm{IrHf}_{\mathrm{x}} \mathrm{O}_{\mathrm{y}}$ catalysts display a comparable stability and the activity of both catalysts decreased by $3 \%$ after $6 \mathrm{~h}$. Conditions: $0.1 \mathrm{M} \mathrm{HClO}_{4}, 5 \mathrm{~mA}$ current. 
a.

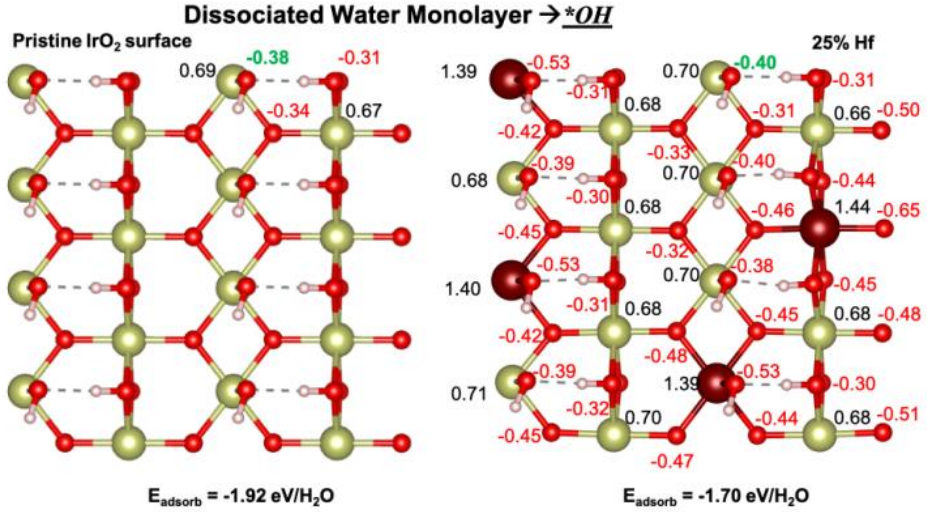

b. $\underline{*}$

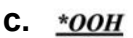
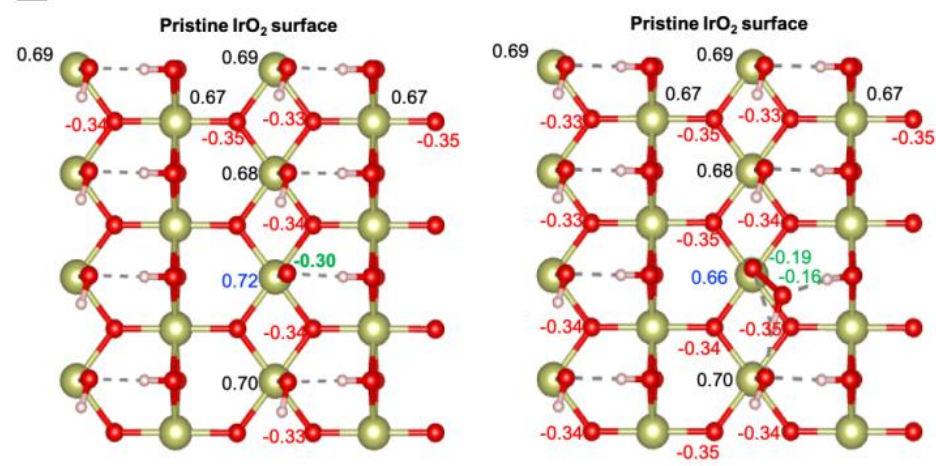

d. $\underline{*} \boldsymbol{O}$

Hf-Doped surface
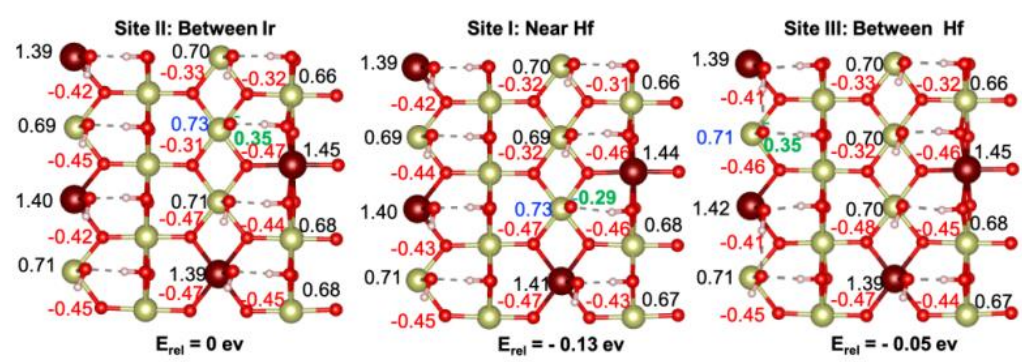

e.

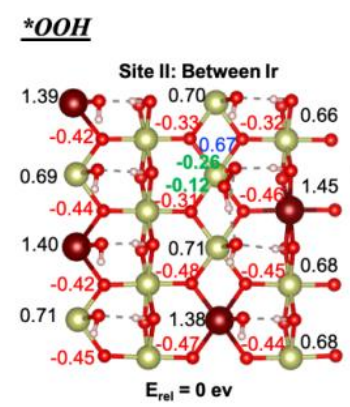

\section{Hf-Doped surface}

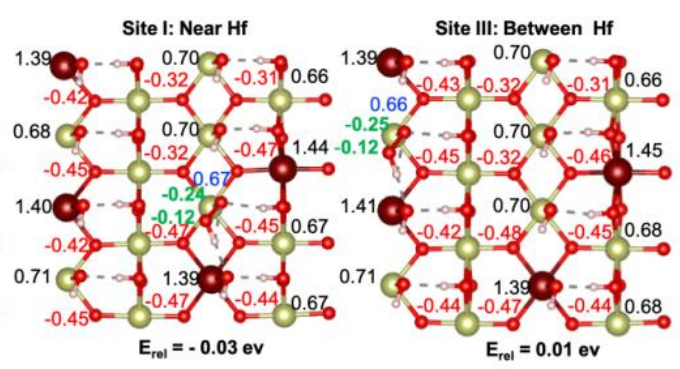

Figure S7. OER intermediates calculation of pristine $\mathrm{IrO}_{\mathrm{x}}$ and $\mathrm{Hf}$-doped $\mathrm{Hf}_{0.25} \mathrm{Ir}_{0.75} \mathrm{O}_{2}$ (110) surfaces: (a) one monolayer of dissociated water at both surface; the formation of the $* \mathrm{O}(\mathrm{b})$ and $* \mathrm{OOH}(\mathrm{c})$ intermediates on pristine $\mathrm{IrO}_{\mathrm{x}}$ surface; (d) the formation of the $* \mathrm{O}(\mathrm{d})$ and $* \mathrm{OOH}(\mathrm{e})$ intermediates on Hf-doped surface at different three sites. Numerical values represent Mulliken charges of relevant Ir/Hf sites(black) and O sites (green). The green and blue Mulliken values are the O sites and Ir sites on three different Ir active sites. 
Table S4 - Formation free energies (in eV) of different OER intermediates shown in Figure 5.

\begin{tabular}{|c|c|c|c|c|}
\hline Intermediates & $\mathrm{IrO}_{2}$ & Site I of $\mathrm{Ir}_{0.75} \mathrm{Hf}_{0.25} \mathrm{O}_{2}$ & Site II of $\operatorname{Ir}_{0.75} \mathrm{Hf}_{0.25} \mathrm{O}_{2}$ & Site III of $\mathrm{Ir}_{0.75} \mathrm{Hf}_{0.25} \mathrm{O}_{2}$ \\
\hline HO* & 0 & 0 & 0 & 0 \\
\hline $\mathbf{O}^{*}$ & 1.97 & 1.87 & 1.99 & 1.94 \\
\hline HOO* & 1.25 & 1.48 & 1.39 & 1.45 \\
\hline
\end{tabular}

\section{References}

1. Zhu, C. Cai, L.; Yang, X.; Kronwitter, C. Guo, L.; Shen, S.; Koel, B. E. Reversible structural evolution of NiCoOxHy during the osygen evolution reaction and identification of the catalytically active phas. ACS Catal. 2018, 8, 1238-1247.

2. Perdew, J. P.; Burke, K.; Ernzerhof, M., Generalized Gradient Approximation Made Simple. Physical Review Letters 1996, 77 (18), $3865-3868$.

3. Kühne, T. D.; Iannuzzi, M.; Del Ben, M.; Rybkin, V. V.; Seewald, P.; Stein, F.; Laino, T.; Khaliullin, R. Z.; Schütt, O.; Schiffmann, F.; Golze, D.; Wilhelm, J.; Chulkov, S.; Bani-Hashemian, M. H.; Weber, V.; Borštnik, U.; Taillefumier, M.; Jakobovits, A. S.; Lazzaro, A.; Pabst, H.; Müller, T.; Schade, R.; Guidon, M.; Andermatt, S.; Holmberg, N.; Schenter, G. K.; Hehn, A.; Bussy, A.; Belleflamme, F.; Tabacchi, G.; Glöß, A.; Lass, M.; Bethune, I.; Mundy, C. J.; Plessl, C.; Watkins, M.; VandeVondele, J.; Krack, M.; Hutter, J. CP2K: An electronic structure and molecular dynamics software package - Quickstep: Efficient and accurate electronic structure calculations. The Journal of Chemical Physics 2020, 152 (19), 194103.

4. VandeVondele, J.; Krack, M.; Mohamed, F.; Parrinello, M.; Chassaing, T.; Hutter, J. Quickstep: Fast and accurate density functional calculations using a mixed Gaussian and plane waves approach. Comput. Phys. Commun. 2005, 167 (2), 103-128.

5. Goedecker, S.; Teter, M.; Hutter, J., Separable dual-space Gaussian pseudopotentials. Physical Review B 1996, 54 (3), $1703-1710$.

6. Nong, H. N.; Falling, L. J.; Bergmann, A.; Klingenhof, M.; Tran, H. P.; Spori, C.; Mon, R.; Timshenko, J.; Zichittella, G.; Knop-Gericke, A.; Piccinin, S.; Perez-Ramirez, J.; Cuenya, B. R.; Schlogl, R.; Strasser, P.; Teschner, D.; Jones, T. E. Key role of chemistry versus bias in electrocatalytic oxygen evolution. Nature 2020, 587, 408-414.

7. Yang, X.; Zhao, F.; Yeh, Y. W.; Selinsky, R. S.; Chen, Z.; Yao, N.; Tully, C. G.; Ju, Y.; Koel, B. E. Nitrogen-plasma treated hafnium oxyhydroxide as an efficient acid-stable electrocatalyst for hydrogen evolution and oxidation reactions. Nat. Commun. 2019, $10,1543$.

8. Cumpson, P. J.; Seah, M. P. Elastic scattering corrections in AES and XPS. II. Estimating attenuation lengths and conditions required for their valid use in overlayer/substrates experiments. Suf. Interface Anal. 1997, 25, 430.

9. SRD 71- NIST electron inelastic mean free path database.

10. Alia, S. M.; Shulda, S.; Ngo, C.; Pylypenko, S.; Pivovar, B. S. Iridum-based nanowires as highly active, oxygen evolution reaction electrocatalysts. ACS Catal. 2018, 8, 2111-2120.

11. Godinez-Salomo, F.; Albiter, L.; Alia, S. M.; Pivovar, B. S.; Camacho-Forero, L. E.; Balbuena, P. B.; Mendoza-Cruz, R.; Arellano-Jimenez, M. J.; Rhodes, C. P. Self-supported hydrous iridium-nickel oxide two-dimensional nanoframes for high activity evolution electrocatalysts. ACS Catal. 2018, 8, 10498-10520.

12.Guo, H.; Fang, Z.; Li, H.; Fernandez, D.; Henkelman, G.; Humphrey, S. M.; Yu, G. Rational design of rhodium-iridium alloy nanoparticles as highly active catalysts for acidic oxygen evolution. ACS nano 2019, 13, 13225-13234.

13. Zhao, Y.; Luo, M.; Chu, S.; Peng, M.; Liu, B.; Wu, Q.; Liu, P.; de Groot, F. M. F.; Tan, Y. 3D nanoporous iridium-based alloy microwires for efficient oxygen evolution in acidic media. Nano Energy 2019, 59, 146-153.

14. Oh, H.S.; Nong, H. N.; Reier, T.; Gliech, M.; Strasser, P. Oxide-supported Ir nanodendrites with high activity and surability for the oxygen evolution reaction in acid PEM water electrolyzers. chem.sci.2015, 6, 3321.

15. Ohno, H.; Nohara, S.; Kakinuma, K,; Uchida, M.; Miyake, A.; Deki, S.; Uchida, H. Remarkable mass activities for the oxygen evolution reaction at iridium oxide nanocatalysts dispersed on tin oxides for polymer electrolyte membrane water electrolysis. J. Electrochem. Soc. 2017, 164, F944. 